\title{
Energia berriztagarrien integrazioa uharte-sareetan
}

\author{
Agurtzane Etxegarai*1 ${ }^{2}$, Pablo Eguia ${ }^{1}$, Esther Torres ${ }^{1}$, Igor Albizu $^{2}$, \\ José Ignacio San Martín ${ }^{2}$ \\ ${ }^{1}$ Bilboko Ingeniaritza Goi Eskola Teknikoa \\ ${ }^{2}$ Eibarko Industria Ingeniaritza Teknikoko Unibertsitate Eskola \\ Euskal Herriko Unibertsitatea (UPV/EHU) \\ *agurtzane.etxegarai@ehu.eus
}

DOI: 10.1387/ekaia.14590

Laburpena: Interkonexio ahuleko sistema elektrikoak eta sare elektriko isolatuak, maiz, energia-iturri berriztagarritan aberatsak izaten dira. Hala ere, elektrizitatearen hornidurak hainbat arazo tekniko eta ekonomiko sortzen ditu, hurbileko beste sistema elektrikoen sostengurik gabe. Artikulu honek deskribatzen ditu, hain zuzen, uharte sareetako dibertsifikazio elektrikoaren alderdiok. Energia berriztagarriak etorkizun jasangarri eta autonomo baten giltza izatera deituak daude uharteetan, teknologiak eskainitako soluzio berrietan oinarrituta. Azkenik, Açores uhartediko Terceira irlaren operazio estatikoa eta dinamikoa aztertzen dira artikuluan, energia berriztagarrien integrazioaren adibide gisara.

Hitz-gakoak: sare ahulak, uharte-sareak, energia berriztagarriak, energia eolikoa.

\begin{abstract}
Isolated power grids or weak interconnections are often gifted with a high density of renewable energy sources. However, the correct operation of those power systems poses both technical and economic issues, because of the lack of support from neighbouring networks. This paper describes those aspects of power supply diversification in weak power grids. Renewable generation is called to be key for a sustainable and autonomous future, based on new technological solutions. Finally, this paper introduces the static and dynamic operation of Terceira island in the Açores archipelago, as an example of renewable power integration in island grids.
\end{abstract}

Keywords: weak power grids, island power grids, renewable energy, wind power. 
Agurtzane Etxegarai, Pablo Eguia, Esther Torres, Igor Albizu, José Ignacio San Martín

\section{SARRERA}

Sistema elektriko garrantzitsuenak elkarkonektaturiko sare sendoak izan arren, azken urteotan interesa handiagotu egin da uharte-sareetan eta interkonexio ahuldun sistemetan, hots, sare ahuletan. Sare nagusiei lotura ahulen bitartez konektaturiko azpisistemak dira sare ahulak; hau da, urrutian kokatutako kargak eta offshore parke eolikoak, baita sare isolatuak ere, uharteak eta mikrosareak bezala.

IEEE 1204 estandarrak bi ikuspegitatik definitzen ditu korronte alternoko sare ahulak, ikuspegi estatikotik eta dinamikotik [1]:

1. Konexio-puntuko potentziarekiko AC sistemaren inpedantzia handia duten sistemak.

2. Sareko potentzia-balantzearekiko inertzia mekanikoa desegokia duten sistemak.

Lehenengo baldintza sare ahul zabaletan betetzen da. Normalki, sareok erdi-tentsiora operatzen dira, $\mathrm{X} / \mathrm{R}$ ratio txikia duten banaketa-linea luzeen bitartez. Uharte-sare txikietan, berriz, ikuspegi estatikoa eta dinamikoa agertzen dira. Energiaren sorkuntza sorgailu-talde gutxiren esku egoten da, gehienbat diesel edo olio astunez elikatutako inertzia baxuko unitate txikiak. Sorgailuen tamaina kargarekiko handia izan ohi da arrazoi ekonomikoak direla eta [2]. Hortaz, sare elkarkonektatuetan baino erreserba-marjina handiagoak behar dira. Eskari-ereduei dagokienez, eskari minimo eta maximoen arteko ratioak baxuak izaten dira. Turismo aktibitatedun uharteek, aldiz, neguan karga baxua eta udan altua izan ohi dituzte.

Sarearen sendotasun estatikoaren ezaugarri nagusia zirkuitulaburreko potentzia da (1. baldintza). Sare ahuletan baxua izan ohi da. Askotan, hala ere, zirkuitulaburreko potentzia konexio-puntuko (aurrerantzean Point of Common Coupling edo PCC) sorgailuaren potentziarekiko adierazten da: Short-Circuit Ratio (SCR) edo zirkuitulaburreko ratioa deritzogu erlazio horri:

$$
S C R=\frac{S_{S C}}{S_{N}}
$$

non $S_{N}$ sorkuntzako zentralaren instalatutako potentzia den eta $S_{S C}$ PCC-ko zirkuitulaburreko potentzia.

Sare elektrikoa sendotzat har daiteke SCR erlazioa 20 [3] eta 25 [4] balioen arteko mugatik gora; sare elektriko ahulen SCRa 6 eta 10 balioen arteko mugatik behera izan ohi da [5].

Bestalde, sare elektrikoen sendotasun dinamikoa (2. baldintza) sistemaren guztizko inertzia konstanteak, $\mathrm{H}$ (segundotan), eta maiztasun-erantzu- 
Energia berriztagarrien integrazioa uharte-sareetan

naren konstante ezaugarriak, $\beta(\mathrm{MW} / \mathrm{Hz})$, adierazten dute. Sistema elektrikoen potentzia/maiztasun ezaugarria sorgailuen droop konstanteen eta kargen maiztasun-erantzunaren menpe dago. Uharte-sareek inertzia baxua eta ahalmen murritza dute maiztasuna erregulatzeko.

Artikulu honek uharte-sareen berezitasunak aztertuko ditu, sor daitezkeen arazo tekniko eta ekonomikoak azpimarratuz. Hala, sistema elektrikoen operazioa kolokan jar daiteke, bereziki energia berriztagarriak integratzeko orduan, ondoren ikusiko den bezala. Sare ahulen modelizazio eta simulazioak ager ditzakeen erronkak ere azpimarratuko dira lan honetan. Azkenik, Açores uhartediko Terceira irla aztertuko da simulazio-eredu adibide gisa, bai operazio estatiko zein dinamikoaren aldetik.

\section{UHARTE-SAREAK ETA ELEKTRIZITATE-SORKUNTZA}

Beste sistema elektriko batzuekiko lotura ahulek edo lotura ezak ez du elektrizitatearen hornidura errazten sare ahuletan oro har, eta bereziki uharte-sareetan. Tentsio eta maiztasunaren erregulazioaren ondoriozko arazo teknikoak sortzen dira. Ekonomikoki ere hainbat desabantaila agertzen dira sistemotan isolamenduak eraginda. Energia berriztagarriek, ordea, paregabeko aukera eskaintzen dute sareen jasangarritasun energetikoa bultzatzeko.

\subsection{Uharte-sareetan agertzen diren arazo teknikoak}

Sare ahuletan elektrizitatearen hornidura etetea ohikoa izaten da, eta etendura horien maiztasuna eta iraupena sare interkonektatuetan baino altuagoa izan ohi da. Horrez gain, sorgailu-unitateak zerbitzuz kanpo izatea ere sarri gertatzen da, eta kanpoko konexio elektrikorik gabeko sareetan arazo larriak ekarri ahal ditu [6]. Sare ahulak gehienbat aireko linea elektrikoz osatuta daudenez, akats elektrikoak sare sendoetan baino sarriago gertatzen dira, eta hala, argitze-denborak ere luzeagoak izaten dira. Perturbazio-patroi horiek, sare ahulen berezko ezaugarriekin batera, tentsio eta maiztasun-erregulazioari eta egonkortasunari lotutako arazo teknikoak sor ditzakete.

\subsubsection{Tentsioaren erregulazioa}

Sistema elektriko ahulek gorabeherak izaten dituzte tentsio-nodoetan, erregimen iraunkorrean zein dinamikoan. Gainera, potentzia erreaktiboaren menpeko sentikortasun handia ageri du tentsioak. Hortaz, potentzia erreaktiboaren kantitate berak (injekzioak zein xurgapenak) sistema sendoetan baino tentsioaren desbideraketa zabalagoak eragiten ditu. 1. iru- 
dian agertzen den sistema sinplifikatuan oinarrituz, potentzia erreaktiboaren eta tentsioaren erregulazioaren arteko erlazioa argi daiteke. Mutur igorlearen (Bus 1) eta hartzailearen (Bus 2) arteko tentsio erorketaren kalkulua:

$$
\Delta V=\frac{R_{S} \cdot P+X_{S} \cdot Q}{E}+j \cdot \frac{R_{S} \cdot P+R_{S} \cdot Q}{E}=\Delta V_{P}+j \cdot \Delta V_{Q}
$$

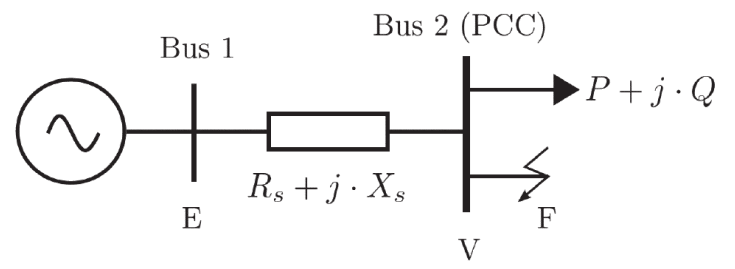

1. irudia. Sistema elektriko baten eredu sinplifikatua.

Transmisio-lineak gehienbat induktiboak dira. Hortaz, potentzia erreaktiboa tentsio-erorketarekiko proportzionala da, eta hala, tentsioaren magnitudea potentzia erreaktiboaren trukaketaren bitartez kontrola daiteke. Sare ahuletan, ordea, X/R ratioa baxuagoa izan ohi da, eta, hori dela eta, potentzia aktiboak zien erreaktiboak daukate eragina tentsioan. Gainera, iturriko inpedantzia altuagoa denez, potentzia erreaktiboaren injekzio txikiek ere eragin adierazgarria dute tentsioan.

\subsubsection{Maiztasunaren erregulazioa}

Oszilazioaren ekuazioak (3) potentzia aktiboa eta maiztasuna lotzen ditu sorkuntza sinkronodun sistema elektrikoetan. Potentzia aktiboaren diskordantziak maiztasunaren aldaketa eragiten du.

$$
2 \cdot H \cdot \frac{d^{2} \Delta}{d t^{2}}=P_{m}-P_{e}-K_{D} \cdot \frac{d \Delta}{d t},
$$

non $H$ inertziaren konstantea den, $\Delta$ karga-angelua, $P_{e}$ potentzia elektromagnetikoa, $P_{m}$ potentzia mekanikoa eta $K_{D}$ moteltze-konstantea.

(3) ekuazioan oinarrituz, zera ondoriozta daiteke: sistemako potentzia aktiboaren aldaketa baten ondorioz, hasierako maiztasun-gradientea (Rate of Change of Frequency - ROCOF - delakoa) eta egoera iraunkorreko maiztasun-desbideraketa, inertzia, sistemaren maiztasun-erantzuna eta erregulazio-kapazitatea, moteltzearen, eta, batez ere, potentzia aktiboaren aldaketaren menpe dagoela. Ikus (4) eta (5) ekuazioak. 


$$
\begin{aligned}
& \text { ROCOF }=\frac{\Delta P}{2 \cdot H}, \\
& \Delta f_{S S}=\frac{\Delta P}{K_{D}+(1 / R)} .
\end{aligned}
$$

Maiztasunaren erregulazioa berez zaila da uharte-sareetan. ROCOF eta erregimen iraunkorreko maiztasunaren desbideraketa (erregulazio primarioa soilik kontuan harturik) handiak sortzen dira. Izan ere, sistema horietan inertzia-konstantea baxua da, erregulazio-kapazitatea baxua eta sorgailuak handiak dira kargaren tamainarekiko. Ondorioz, maiztasunaren desorekak gerta daitezke [7], batez ere energia berriztagarrien penetrazio altuko uharteetan.

\subsubsection{Egonkortasuna}

Tentsio eta maiztasun arazoek desegonkortasuna eragin dezakete. Maiztasun-desoreka ohikoagoa izaten da uharte-sareetan, eta aldiz, tentsiodesegonkortasuna, sare ahul zabaletan. Bestalde, egonkortasun iragankorra ere kolokan egon daiteke sare ahuletan zirkuitulaburrak gertatzen direnean. Izan ere, zirkuitulaburreko potentzia baxuko puntuetan baxua izaten da tentsio-hutsaren magnitudea. (6) ekuazioan ikus daiteke hori zirkuitulabur trifasiko zuzenaren kasuan. Horrez gain, egonkortasun iragankorra azkarrago gal daiteke uharte-sareetan inertziaren balio baxuak eta akatsen iraupen luzeagoa dela eta. Sare isolatu txikietan tentsio-hutsak sistema osora zabaldu ohi dira, distantzia elektriko txikiak direla eta.

$$
V_{d i p} \text { (p.u.) }=V_{p f, B u s 1} \cdot \frac{Z_{f}}{Z_{s 1}+Z_{f}}=V_{p f, B u s 1} \cdot \frac{Z_{f}}{\frac{V_{p f, P C C}}{S_{S C, P C C}}+Z_{f}},
$$

non $Z_{f} \mathrm{~F}$ akats-puntuko inpedantzia den, $Z_{s 1}$ sekuentzia positiboko iturriko inpedantzia, $V_{p f}$ akats aurreko tentsioa, eta $S_{S C}$ zirkuitulaburreko potentzia.

\subsection{Uharte-sareetan agertzen diren arazo ekonomikoak}

Uharte-sareetako sistema elektrikoan berebiziko garrantzia du alderdi ekonomikoak. Gainontzeko sareetatik isolatuta egoteak elektrizitatearen sorkuntza garestitzen du, elektrizitatea tokian sortu behar baita. Operazio- eta erregai-kostuak (inportazioa eta garraioa) ere igo egiten dira. Gainera, uharte-sare gehienek \%30-40 arteko sorkuntza-marjinekin lan egiten dute fidagarritasuna ziurtatu ahal izateko. Hortaz, elektrizitatearen sorkuntza elkarkonektaturiko sareetan baino \%15-20 garestiagoa izan ohi da [8]. 
Agurtzane Etxegarai, Pablo Eguia, Esther Torres, Igor Albizu, José Ignacio San Martín

Frantzian Electricité de France (EDF) operatzaileak kudeatutako Systèmes Energétiques Insulaires (SEI) sare isolatuen kasuan, gainkostuak bikoiztu egiten ditu metropoliko prezioak [9]. Hala ere, solidaritate-politikak aplikatzea ohizkoa izaten da sare ahuletan eta eredu ekonomiko egokituak sustatzen dira.

Irletan, merkatu eta inbertsioen egoera populazioaren dentsitateari estuki loturik daude; populazioa zenbat eta txikiagoa, merkatua are eta txikiagoa da. Hortaz, energia sistema jasangarriak bultzatzea erronka bihurtzen da eta irla gehienek olioz elikatutako Diesel motorrak erabiltzen dituzte elektrizitate-sorkuntzarako [8].

Aipaturiko desabantaila ekonomikoek grid codean edo arau teknikoetan ere eragina daukate. Alde batetik, sare ahuletan berebiziko garrantzia dauka energia berriztagarrietan oinarritutako sorgailuek tentsioaren eta maiztasunaren zerbitzu osagarrietan parte hartzeak. Horrek sistemaren operazioa garestitzen du. Bestalde, sorgailuek bete beharreko arau zorrotzek fabrikatzaileen gastuak igoarazten dituzte. Alderdi biek eragin zuzena dute berez ere ekonomikoki murriztuta dauden sistema elektrikoetan, hala nola, uharteetan.

\subsection{Energia berriztagarrien integrazioa uharte-sareetan}

Hainbat ikerketa burutu dira energia berriztagarrien integrazioa mugatzen duten faktoreak zehazteko asmoz. Lan gehienak energia eolikoan oinarritu dira. Energia eolikoaren muga ideala uharte-sare batean eskariaren aldiuneko potentzia izango litzateke [10]. Errealitatean, muga tekniko eta ekonomikoez gain, baliabidearen muga ere aipatzen dira literaturan [11]. Energia-iturriak baliagai gisa ez dira arazo uharte-irla gehienetan. Muga ekonomikoek, ordea, berebiziko garrantzia dute sare isolatuetan. Eta penetrazio-ratioa gora joan ahala, txarrera egiten dute [12]. Muga teknikoei begira, tentsioaren eta maiztasunaren erregulazioa, bai eta egonkortasuna, berez egon daitezke kolokan sare ahuletan. Arazo horiek areagotu egiten dira energia berriztagarriak konektatzean, baliabideak zeharo aldakorrak eta aurresangarritasun txikikoak baitira. Inguruko sistema elektrikoekin dauden energia-elkatrukaketak txikiak dira, eta ezin dute portfolio deituriko efektuaz profitatu [13]. Horrenbestez, elektrizitatearen hornidura, fidagarritasuna, segurtasuna eta kalitatea erronka handi bihurtzen dira uharte-sareetan energia berriztagarriak instalatu nahi direnean [14]:

- Energia berriztagarrien sorkuntza ezin da aurretiaz planifikatu eta potentzia-mugak dituzte baliabide naturala desagertzen denean. Gainera, sorkuntza konbentzionaleko sorgailuek potentziaren minimo teknikoak gorde behar dituzte [15].

- Energia berriztagarrietan oinarritutako uharteetan, eskariak eta sorkuntzak aldaketa azkarrak jasaten dituzte sarri [16], energia-iturrien 
Energia berriztagarrien integrazioa uharte-sareetan

aldakortasuna eta aldizkakotasuna dela eta. Diesel sorgailuek ezin diete beti aldaketa horiei eutsi, euren karga-maila guztizko kapazitatearen \%50-75ekoa izaten baita [17].

- Tamaina txikiko eta erdi-tentsioko banaketa-saredun sistemetan sorkuntza berriztagarria kargetatik gertu kokatu ohi da. Beraz, elektrizitatearen kalitatea kaskarra izan daiteke. Horrez gain, energia-iturrion aldakortasunak tentsioaren fluktuazioak (flicker), harmonikoak, tentsio-hutsak eta tentsio-desorekak sor ditzake [18].

- Energia berriztagarriak berezko inertziarik gabeko sorgailu ezsinkronoetan oinarrituta daude. Beraz, potentzia-aldaketen ondoriozko maiztasun-desbideraketak handiagoak izan daitezke. Sorgailu sinkronoak ordezkatzen dituztenez, maiztasunaren eta tentsioaren kontrol-funtzioak ere euren gain hartzea eska diezaiekete operatzaileek.

Sistema elektriko batzuetan mugatu egin dute energia berriztagarrien penetrazioa, arazo teknikoak ekiditeko asmoz. Mugak sistema autonomo bakoitzeko baldintzen arabera ezarrita daude, bai unitate konbentzionalen zein berriztagarrien ezaugarri, tamaina eta teknologiaren arabera. \%15eko proportzioa muga maximotzat dago oro har [19]. Sistema elektriko batzuetan, energia berriztagarrien penetrazio maximoa arau bihurtu dute. EDF konpainiak energia ez-aurresangarriak \%30era mugatzen ditu denbora errealean [20]. Greziako uharte autonomoetan, hala nola Kretan, energia eolikoaren sorkuntza aldiuneko eskariaren \%30era mugatuta dago [21]. Irlandako Electricity Supply Board (ESB) erakundeak proposatu zuen egunez energia eolikoa aldiuneko kargaren \%30era mugatzea eta gauez penetrazio handiagoak onartzea [22]. Sardinian 1200 MW-eko karga minimorako $400 \mathrm{MW}$ da muturreko proportzioa [23]. Australiako sistema elektriko isolatu txikietan, Tasmanian kasu baterako, aldiuneko kargaren \%40 onartzen da [24]. Ondorioz, energia berriztagarriek noiz edo noiz sortzen duten potentzia mugatu behar dute (curtailment) energia-iturria alferrik galduz.

Hala ere, curtailment teknika ez da bide optimoa, energia berriztagarrien integrazioa maximizatzea uharte-sareen etorkizun energetikorako irtenbide egokia delako. Hala, hornikuntza autonomoa eta segurua ziurtatu ahal izango lirateke [14]. Horrenbestez, ekimen berriak eta proiektu berriztatzaileak sustatu dira azken urteotan uharte-sareetan, hala nola: energiaren kudeaketa eraginkorreko sistemak, baliabideen aurresangarritasuna eta eskariaren kudeaketa barne [25]; energia berriztagarrien ustiapen optimoa eta epe motzeko operazioa [26, 13]; sare elektrikoaren eta aktiboen hobekuntza; zentral termiko malguagoak eta performantzia altukoak [8]; kontrol algoritmo berriak bihurgailuetan [27, 28, 29]; edo potentzia aktiboaren metaketa (adib. bateriak, ponpaketa, inertzia-bolanteak...) [14]. Horrez gain, sistema-operatzaileek baldintza tekniko zorrotzak ezarri dituzte grid code 
Agurtzane Etxegarai, Pablo Eguia, Esther Torres, Igor Albizu, José Ignacio San Martín

arauetan, maiztasun eta potentzia aktiboari edo/eta tentsio eta potentzia erreaktiboari dagokionez. Sorkuntza sinkrono konbentzionalen gisan, gaur egun energia berriztagarrietan oinarritutako sorgailuei ere eskatzen zaie sistemaren kontrolean eta segurtasunean aktiboki parte hartzea.

\section{SARE ELEKTRIKO AHULEN MODELIZAZIOA ETA SIMULAZIOA}

Sare elektriko ahulen modelizazio eta simulazioa zeharo garrantzitsuak dira aurretiaz ikertu ahal izateko energia berriztagarrietan oinarritutako sorgailuen eta sistema elektrikoaren arteko elkarrekintza. Eredu elektrikoak erabiltzeko orduan, honako alderdiak izan behar dira gogoan:

- Sareko kargaren eta sorkuntzaren arteko distantzia elektrikoak txikiak izanik, funtsezkoak dira elkarren arteko dinamikak.

- Epe motzeko dinamikak direla eta, sorgailuen konexio-puntuan SCR ratioa baxua denean, beharrezkoa izan daiteke eredu elektromagnetikoak erabiltzea.

- Tentsio eta korronte-desorekak ager daitezkeenez, gomendagarria izan daiteke eredu trifasikoak erabiltzea.

- Zaila gerta daiteke sareko aktiboen datu teknikoak lortzea, batez ere sorgailuen ezaugarri dinamikoei dagokienez. Askotan, konexiopuntuko tentsioa eta zirkuitulaburreko tentsioa baino ez ditu argitaratzen sistemaren operatzaileak.

Horrez gain, sorgailu berriztagarrien modelizazioak ere hainbat erronka dakartza, hala nola [28, 29]:

- Sorgailu ez-sinkronoak potentziako elektronikan oinarrituta daude eta kontrol sistemak eta algoritmoak fabrikatzailearen jabegokoak dira. Horrenbestez, ereduak ez dira publikoak izaten.

- Energia berriztagarrietan oinarritutako zentralak sorkuntza-unitate askok osatzen dituzte. Sorgailuen agregazioa araudi askotan onartuta egon arren, egoera batzuetan (hots, haize-abiadura ezberdinak, parke eoliko handiak, feeder ugaridunak, etab.) agregazioa ez da egokia.

- Seinaleko txikiko performantzia ikertzeko eredu publikorik ez da aurkeztu.

Azken urteetan, energia berriztagarrietan oinarritutako sorgailuen eredu generikoak proposatu dituzte Western Electricity Coordinating Council (WECC) eta IEC erakundearen TC88 komiteak, fabrikatzaileen kaxa beltzeko eredu pribatuak alde batera utziz. Hasiera batean, aerosorgailuen ereduetan jarri zen arreta, baina denborarekin energia-iturria edozein dela ere inbertsore eredu bakarra proposatu dute WECC erakundetik [29]. 


\section{AÇORES UHARTEDIKO TERCEIRA IRLA}

Terceira uharteak $397 \mathrm{~km}^{2}$-ko azalera du, 56477 biztanlerekin [30]. Puntako karga 35 MW gainetik dago eta haraneko karga 14 MW inguruan. Elektrizitatea banatzeko sarea nahiko erradiala da, nahiz eta azken urteetan egin diren hobekuntzei esker gurutzetasun handiagoa lortu den. Tentsiorik altueneko linea $30 \mathrm{kV}$-ekoa da. Energiaren hornikuntza zentral termiko bakar batean oinarritzen da, Belo Jardim deiturikoa, 76 MVA-ko kapazitatea duena. Horrez gain, tamaina txikiko zentral hidroelektrikoak ere badaude (Cidade, Nasce d'Agua eta Sao Joao de Deus) eta 9 MW-eko parke eoliko bat, Serra do Cume. 2. irudian erakusten da uharteko sare elektrikoaren hari bakarreko eskema.

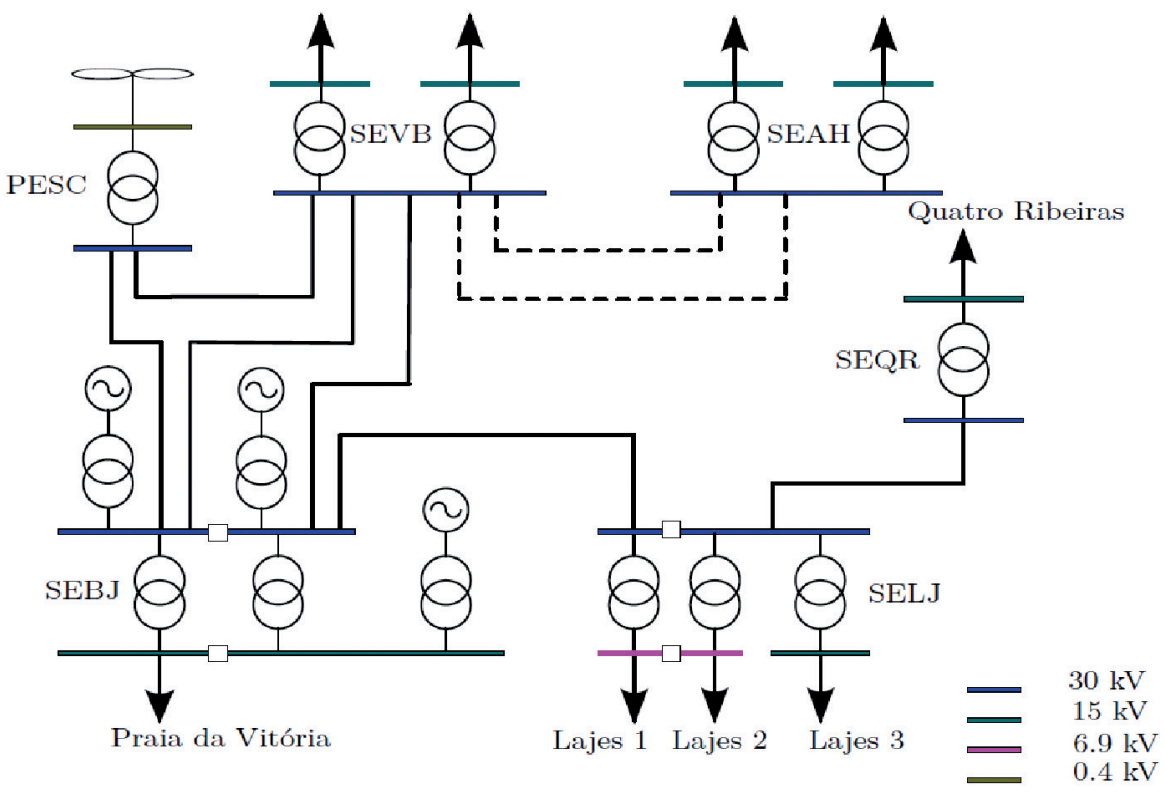

2. irudia. Terceira uharteko hari bakarreko diagrama.

Serra do Cumeko parke eolikoan 900 kW-eko 10 ENERCON E44 motako aerosorgailu daude. Abiadura aldakorrekoak eta kaxa biderkatzailerik gabekoak dira, iman iraunkorretan oinarrituta (PMSG - Permanent Magnet Synchronous Generator-). Diesel motorretan oinarritutako zentral termikoan 10 sorgailu sinkrono daude. SEXS delako tentsio-erregulagailua eta DEGOV1 abiadura-erregulagailuak gehitu dira sorgailu bakoitzean.

Terceira uhartearen operazioa aztertu da lan honetan, errejimen egonkorrean zein iragankorrean. Digsilent Power Factory simulazio- 
Agurtzane Etxegarai, Pablo Eguia, Esther Torres, Igor Albizu, José Ignacio San Martín

softwarea erabili da. 5 kasu definitu dira karga-egoeraren (puntako karga PK eta haran-karga $\mathrm{HK}$ ) eta sorkuntza-egoeraren arabera (haizerik ez $0 \mathrm{H}$, guztizko $\% 50$ eko sorkuntza eolikoa $50 \mathrm{H}$ eta guztizko $\% 100$ eko sorkuntza eolikoa 100H). Aztertu diren kasuak 1. taulan ikus daitezke. Erreserba birakari bat ere definitu da, aldioro sistemako edozein sorgailuren galera ordezkatzeko bestekoa. Sorkuntza konbentzionalaren hornidura ikuspegi ekonomikoa jarraituz burutu da, unitateen minimo teknikoak errespetatuz $[31,32]$.

1. taula. Terceira uharteko azterketa-kasuen laburpena.

\begin{tabular}{cccccc}
\hline Kasua & PK & HK & OH & $50 \mathrm{H}$ & $100 \mathrm{H}$ \\
\hline 1 & $\checkmark$ & & $\checkmark$ & & \\
2 & $\checkmark$ & & & $\checkmark$ & \\
3 & $\checkmark$ & & & & $\checkmark$ \\
4 & & $\checkmark$ & $\checkmark$ & & \\
5 & & $\checkmark$ & & $\checkmark$ & $\checkmark$ \\
6 & & $\checkmark$ & & & $\checkmark$ \\
\hline
\end{tabular}

\subsection{Errejimen egonkorreko operazioa}

Egoera egonkorrean, tentsio-mailak 0,9-1,1 p.u. tartean mantentzen dira, sareko kodeak zehazten duen bezala. Batez besteko tentsio-mailarik altuenak 4 eta 5 kasuetan lortzen dira, haran-kargan eta haize gutxirekin. Tentsiorik altuenak, berriz, puntako eskariko egoeretan daude. Lineak eta transformadoreak ondo dimentsionatuta daude, ez baita gainkarik gertatzen sarean.

N-1 kontingentzia egoerak definitu dira banakako lineen eta transformadoreen desarrak kontuan izanik. Lajes (SELJ) eta Quatro Ribeiras (SEQR) azpiestazioak elektrizitaterik gabe geratzeko arriskua agertzen da, sarea erradiala denean. N-2 kontingentzien kasuan, linea bikoitzen galerak Angra do Heroismo (SEAH) azpiestazioaren galera eragiten du eta garraio-linea batzuk gainkargatu egiten dira potentzia-fluxua desbideratzean.

Zirkuitulaburreko potentziarik altuena 1 kasuan sortzen da Belo Jardim azpiestazioan (SEBJ), 285,78 MVA-ko balioarekin. Zirkuitulaburreko potentziarik baxuenak, aldiz, 6 kasuan agertzen dira. $30 \mathrm{kV}$-eko sarean 37,39 MVA da baliorik txikiena, eta $15 \mathrm{kV}$-eko sarean, berriz, 30,49 MVA. Bi balioak Quatro Ribeiras azpiestazioan sortzen dira. 
Energia berriztagarrien integrazioa uharte-sareetan

\subsection{Errejimen iragankorreko operazioa}

Errejimen iragankorreko operazioan, sorgailuen galera, karga-galera eta zirkuitulaburrak aztertu dira.

Kasu bakoitzerako, linean dagoen sorgailurik handienaren galera simulatu da. Emaitzak 3. irudian ageri dira. 6 kasua ez da ageri, egonkortasuna galtzen baitu sistemak. Egoerarik larrienak haran-kargan eta sorkuntza eolikoaren penetrazio altuarekin lortzen dira. Hau da, 5. kasuan. Hala, maiztasunaren deribatuak (ROCOF) balio handiak hartzen ditu, $-2,32$ $\mathrm{Hz} / \mathrm{s}$ arte, eta gutxieneko maiztasunaren balioa 48,06 Hz da. Egoera egonkorreko baliorik baxuena 49,41 Hz da, baina kontuan izan behar da tarte horretan erregulazio primarioak baino ez duela oraindino parte hartu. Bestalde, uharte-sareetan ohikoa izaten da deslastatze-prozedura (ingelesez, Under Frequency Load Shedding UFLS). 4. irudian ikus daiteke maiztasunaren eboluzioa sorkuntza galtzean. Bertan, oinarriko kasua bi deslastatze modurekin alderatu da. UCTE (Union for the Coordination of the Transmission of Electricity) erakundeko irizpidea mailakako deslastatze deterministan oinarritzen da. Irizpide hau aplikatuz gero, maiztasun minimoaren balioa asko gutxitzen da. Baina maiztasunak balio altua hartzen du errekuperaziorako bidean. Maila bakarreko deslastatzearekin, aldiz, emaitza hobea lortzen da.

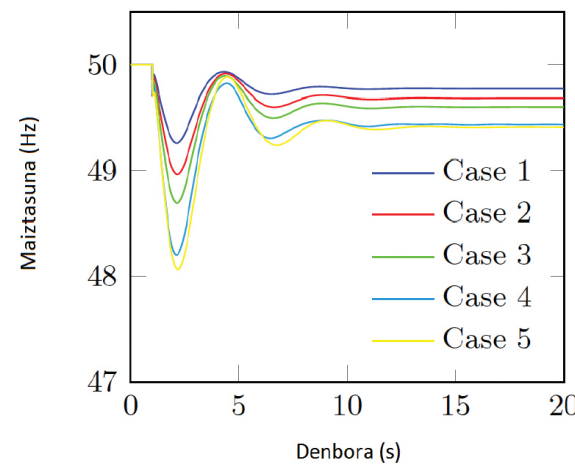

3. irudia. Maiztasun-desbideraketak sorkuntza galtzean.

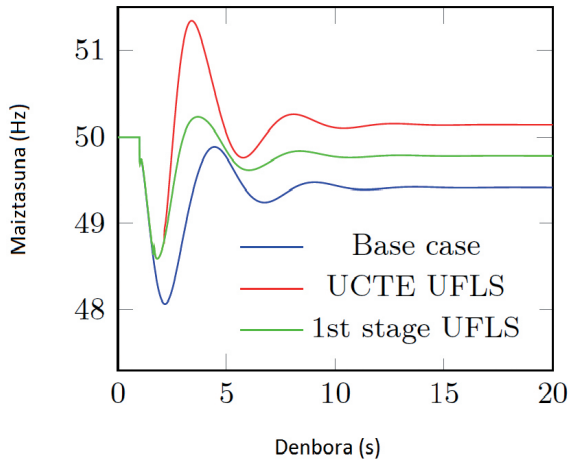

4. irudia. Maiztasun-desbideraketak 5 kasurako.

Bestalde, karga-galerak ere simulatu dira, gehienezko gainmaiztasunak aztertu ahal izateko. 6 kasuan lortzen dira baliorik altuenak: 2,2 Hz/s-ko maiztasunaren deribatua, eta maiztasun maximoa $51,4 \mathrm{~Hz}$. Oinarrizko kasuan, gainmaiztasunen kasuan sortzen duten potentzia mugatzeko logika daukate aerosorgailuek. Logika hori desgaituta, potentzia-injekzio hutsak dira, eta, horrenbestez, maiztasun-desbideraketak handiagoak dira: $2,3 \mathrm{~Hz} / \mathrm{s}-\mathrm{ko}$ ROCOF eta $51,89 \mathrm{~Hz}$-eko maiztasun maximoa. 
Agurtzane Etxegarai, Pablo Eguia, Esther Torres, Igor Albizu, José Ignacio San Martín

Terceira uharteko operatzailearen arabera, 2012an gertatutako tentsiohutsak magnitude txikikoak eta $200 \mathrm{~ms}$ baino iraupen motzagokoak izan ziren [32]. Hala ere, 250 ms-ko zirkuitulaburrak eragin dira simulazio-ereduan, baldintzarik txarrenak emulatu ahal izateko. Babesgailuen ekintza ez da kontuan izan. Egonkortasun iragankorrari eusten zaio kasu guztietarako. Parke eolikoaren barretan aplikatutako akatsak dira arriskutsuenak, batez ere puntako kargapean. Zirkuitulaburraren iraupena luzatuz gero, hutsa argitzean gaintentsio larriak ager daitezke eta berreskuratzea geldotzen da. 500 ms-tik gorako zirkuitulaburren kasuan, egonkortasun iragankorra galtzeko arriskua dago (ikus 5. irudia).

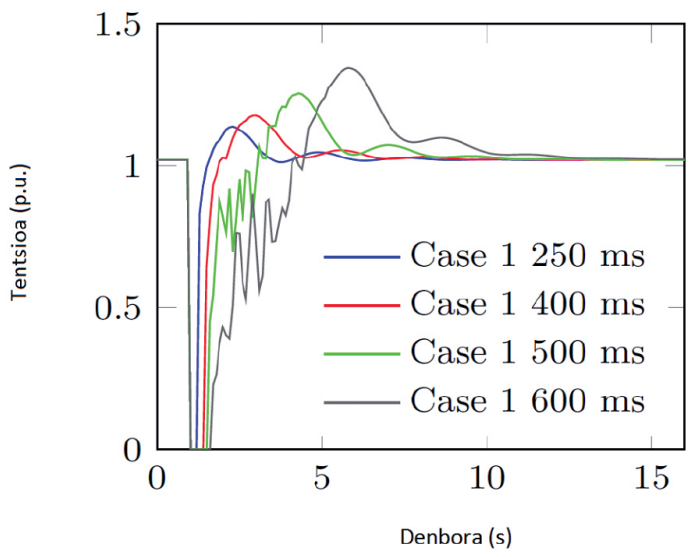

5. irudia. Tentsio-hutsen magnitudea, zirkuitulabur trifasikoa PESC parke eolikoan.

Zirkuitulaburren ondorioz, maiztasuna ere aldatu egiten da. Zenbat eta akatsaren iraupena handiagoa izan, maiztasun-desbideraketa ere handiagoa agertzen da. Korapilo sendoetan maiztasuna asko aldatzen da: 51,86 Hz eta 48,74 Hz-eko muturreko balioak azaltzen dira, maiztasunaren deribatua $5 \mathrm{~Hz} / \mathrm{s}$ ingurukoa izanik.

\section{ONDORIOAK}

Uharteetako sare ahulak elektrizitatez etenik gabe eta kalitatez hornitzeak hainbat erronka ekartzen ditu alderdi tekniko eta ekonomikotik. Hala ere, energia berriztagarriak aukera egokia izan daitezke arazoak gainditu eta sistema isolatuen autonomia energetikoa bermatzeko. Açores uhartediko Terceira irlaren kasuan, instalatutako energia eolikoa puntako eskariarekiko \%30 da. Sistemako inertzia eta zirkuitulaburreko potentzia baxuak 
Energia berriztagarrien integrazioa uharte-sareetan

direnean, behin-behineko maiztasun- eta tentsio-desbideraketa handiak sortzen dira. Errejimen iraunkorreko operazioa egokia da, ordea.

\section{ESKER ONAK}

Artikulu honek UPV/EHUk finantzatutako EHU13/66 proiektuaren baitan garatutako lana aurkezten du.

\section{BIBLIOGRAFIA}

[1] «IEEE Guide for Planning DC Links Terminating at AC Locations Having Low Short-Circuit Capacities», IEEE Std 1204-1997, p. i-, 1997.

[2] G. DELILLE, B. FRANCOIS eta G. MALARANGE. 2012. «Dynamic Frequency Control Support by Energy Storage to Reduce the Impact of Wind and Solar Generation on Isolated Power System's Inertia», IEEE Trans. Sustain. Energy, vol. 3, n. ${ }^{\circ}$ 4, pp. 931-939.

[3] M.F. FARIAS, P.E. BATTAIOTTO eta M.G. CENDOYA. 2010. «Wind Farm to Weak-Grid Connection using UPQC custom power device», en Industrial Technology (ICIT), 2010 IEEE International Conference on, pp. 1745-1750.

[4] J.O. TANDE, G. DI MARZIO eta K. UHLEN. Nov. 2007. «System Requirements for Wind Power Plants», SINTEF Energy Research.

[5] N.P.W. STRACHAN eta D. JOVCIC. 2010. «Stability of a Variable-Speed Permanent Magnet Wind Generator With Weak AC Grids», Power Deliv. IEEE Trans. On, vol. 25, n. ${ }^{\circ}$ 4, pp. 2779-2788.

[6] I.D. MARGARIS, A.D. HANSEN, N.A. CUTULULIS, P. SORENSEN eta N.D. HATZIARGYROU. 2011. «Operation and Control of Wind Farms in Non-Interconnected Power Systems», en Wind Farm-Impact in Power System and Alternatives to Improve the Integration, vol. Chapter 8, InTech.

[7] E. HAESEN, F. MINNE, J. DRIESEN eta M.H.J. BOLLEN. Nov. 2015. «Hosting capacity for motor starting in weak grids», Int. Conf. Future Power Syst., pp. 1-6.

[8] H. HAEDER. Jun. 2012. «EU Islands: towards a sustainable energy future», EURELECTRIC, D/2012/12.105/24.

[9] D. MARÍN. 2009. «Intégration des éoliennes dans les réseaux électriques insulaires», Ecole Centrale de Lille, Laboratoire d'Electrotechnique et d'Electronique de Puissance de Lille, Lille, France.

[10] C.A. BELLÉS. 2012. «Electric Vehicles charging from surplus wind power in non-connected islands», Department of Mechanical and Aerospace Engineering, University of Strathclyde.

[11] P. GARDNER eta I. PAPADOPOULOS. 2012. «The limiting factors for wind integration», Copenhagen. 
Agurtzane Etxegarai, Pablo Eguia, Esther Torres, Igor Albizu, José Ignacio San Martín

[12] M.H. AHMED. 2012. «New Models and Analytical Frameworks for Power Systems with Wind Generation Penetration», University of Waterloo, Waterloo, Ontario, Canada.

[13] C.K. SIMOGLOU, E.G. KARDAKOS, E.A. BAKIRTZIS, D.I. CHATZIGIANNIS, S.I. VAGROPOULOS, A.V. NTOMARIS, P.N. BISKAS, A. GIGANTIDOU, E.J. THALASSINAKIS, A.G. BAKIRTZIS eta J.P.S. CATALÃO. Oct. 2014. «An advanced model for the efficient and reliable short-term operation of insular electricity networks with high renewable energy sources penetration», Renew. Sustain. Energy Rev., vol. 38, pp. 415-427.

[14] A.W. BIZUAYEHU, E.M.G. RODRIGUES, S.F. SANTOS, J.P.S. CATALAO eta J. CONTRERAS, «Assessment on baseline and higher order grid security criteria: Prospects for insular grid applications», en 2014 IEEE PES General Meeting / Conference Exposition, 2014, pp. 1-5.

[15] S.A. PAPATHANASSIOU eta N.G. BOULAXIS. Abr. 2006. «Power limitations and energy yield evaluation for wind farms operating in island systems», Renew. Energy, vol. 31, n. ${ }^{\circ}$ 4, pp. 457-479.

[16] STORIES project. Mar. 2009. «Workpackage 2: Market applications in specific island power systems».

[17] N. HAMSIC, A. SCHMELTER, A. MOHD, E. ORTJOHANN, E. SCHULTZE, A. TUCKEY eta J. ZIMMERMANN. 2007. «Increasing Renewable Energy Penetration in Isolated Grids Using a Flywheel Energy Storage System», en International Conference on Power Engineering, Energy and Electrical Drives. POWERENG 2007, 2007, pp. 195-200.

[18] K. BURMAN, D. OLIS, V. GEVORGIAN, A. WARREN, R. BUTT, P. LILIENTHAL eta J. Glassmire. Sep. 2011. «Integrating Renewable Energy into the Transmission and Distribution System of the U.S. Virgin Islands», Energy Development in Island Nations EDIN, NREL/TP-7A20-51294.

[19] J. KUMAGAI. May 2013. «The smartest, greenest grid», IEEE Spectr., vol. 50, n. $^{\circ} 5$, pp. $42-47$.

[20] «Arreté du 23 avril 2008 relatif aux prescriptions techniques de conception et de fonctionnement pour le raccordement au réseau public de transport d'électricité d'une installation de production d'énergie électrique», Ministère Ecol., jul. 2010.

[21] J.K. KALDELLIS. Ago. 2008. «Maximum wind potential exploitation in autonomous electrical networks on the basis of stochastic analysis», J. Wind Eng. Ind. Aerodyn., vol. 96, n. ${ }^{\circ}$ 8-9, pp. 1412-1424.

[22] D. WEISSER eta R.S. GARCIA. Jul. 2005. «Instantaneous wind energy penetration in isolated electricity grids: concepts and review», Renew. Energy, vol. 30, n. ${ }^{\circ} 8$, pp. 1299-1308.

[23] ERIC VALES. 2012. Actu-Environment.

[24] M. CHARLET. 22 jun. 2009. «SEI EDF Guadeloupe», presentado en INTERREG IV Caraïbes.

[25] M. HARPER. Mara 2013. «Review of Strategies and Technologies for Demaand-Side Management on Isolated Mini-Grids», Lawrence Berkeley Na- 
Energia berriztagarrien integrazioa uharte-sareetan

tional Laboratory, Schatz Energy Research Center, California, USA, LBNL$6223 \mathrm{E}$.

[26] K. DE VOS, A.G. PETOUSSIS, J. DRIESEN eta R. BELMANS. Feb. 2013. «Revision of reserve requirements following wind power integration in island power systems», Renew. Energy, vol. 50, pp. 268-279.

[27] H. VASCONCELOS, C. MOREIRA, A. MADUREIRA, J.P. LOPES eta V. MIRANDA. Mar. 2015. «Advanced Control Solutions for Operating Isolated Power Systems: Examining the Portuguese islands.», IEEE Electrification Mag., vol. 3, n. ${ }^{\circ}$ 1, pp. 25-35,.

[28] P. RAVALLI eta J. LEUNG. 2011. «Dynamic model requirements and model validation in the Australian National Electricity Market», en 2011 IEEE Power and Energy Society General Meeting, pp. 1-5.

[29] WECC Renewable Energy Modeling Task Force. Sep. 2012. «Generic Solar Photovoltaic System Dynamic Simulation Model Specification», Western Electricity Coordinating Council Modeling and Validation Work Group, Sandia Contract \#1047506.

[30] «Isla Terceira», Wikipedia, la enciclopedia libre. 31-mar-2015.

[31] MINISTERIO DE INDUSTRIA, ENERGÍA ETA TURISMO. 2012. Resolución de 24 de julio de 2012, de la Secretaría de Estado de Energía, por la que se aprueba la modificación de los procedimientos de operación del Sistema Eléctrico Peninsular (SEP) P.O.-3.1; P.O.-3.2; P.O.-9 y P.O.-14.4 y los procedimientos de operación de los Sistemas eléctricos Insulares y Extrapeninsulares (SEIE) P.O. SEIE-1 P.O. SEIE-2.2; P.O. SEIE-3.1; P.O. SEIE-7.1; P.O. SEIE-7.2; P.O. SEIE-8.2; P.O. SEIE-9 y P.O. SEIE-2.3 para su adaptación a la nueva normativa eléctrica., vol. Num. 191.

[32] «Caracterização da rede de transporte e distribução em AT e MT 2012», Electricidade da Madeira, mar. 2012. 